Article

\title{
Sustainable and Integrated Development-A Critical Analysis
}

\section{Christopher J. Koroneos * and Dimitri Rokos}

Interdisciplinary Postgraduate Program 'Environment and Development', School of Rural and Surveying Engineering, National Technical University of Athens, Iroon Polytecniou 9, Zografou 157 80, Athens, Greece; E-Mail: drdrok@central.ntua.gr

* Author to whom correspondence should be addressed; E-Mail: koroneos@chemeng.ntua.gr; Tel.: +30-210-7723085; Fax: +30-210-7723085.

Received: 12 September 2011; in revised form: 2 January 2012 / Accepted: 3 January 2012 / Published: 12 January 2012

\begin{abstract}
The words "Sustainable Development" are frequently used by very lightly, to the extent that they have lost their meaning. There is a presumption that for any perspective analysis or any development proposal, these two words are the most appropriate. Sustainability has been incorporated in the objectives of many studies. The historical model of industrialized societies in the 19th and 20th centuries served as the central notion of what constitutes development in both the cost-effectiveness and equity perspectives. According to some analysts, this path represents the model for global prosperity. However, a number of growing parallel literatures recognize the importance of diverse development pathways in achieving an environmentally and socio-economically better world. The term sustainable development does not bring forward all aspects of development. A new term that incorporates the wellbeing of all citizens through economic development and the preservation of the environment is needed. A "Worth-living Integrated Development" could be a term that combines economic development, social development and environmental protection. A Worth-living Integrated Development may be achieved only when human societies decide to create necessary presuppositions - at the educational, research, economic, social, political, technical/technological and environmental levels-for a better world, based on the human values of peace, justice, solidarity, political, economic and social democracy and ethics, respect for nature and for the variety of cultures of all human beings.
\end{abstract}


Keywords: sustainable development; worth-living integrated development; integrated development

\section{Introduction}

The term sustainability was first coined in 1980 by the International Union for Conservation of Nature and Natural Resources (IUCN). In 1987 the 'Brundtland Report' (the report of the United Nations Commission on Environment and Development) established the concept of sustainable development as "development that meets the needs of the present without compromising the ability of future generations to meet their own needs" [1].

In examining the major environmental problems facing the world and the appropriate responses to them, the Brundtland Report established the framework under which the twin requirements of environmental protection and economic development could be integrated. Sustainable development rapidly became the key principle underpinning official environmental policy at both national and international levels.

However, there is considerable disagreement among scholars on conceptual grounds and on its functionality [2]. It is a very important fact that many scholars and practitioners define sustainability as an integrated concept that takes into consideration three elements: economic development, ecological conservation (sustainability) and social justice (equity) [2-12].

More recently, with the shift in emphasis towards practical and operational aspects, the literature has begun to look at synergies and trade-offs between the three goals.

In addition to the Burtland definition, other definitions have been proposed and have gained acceptance. The 'Caring for the Earth definition' brings into consideration the capacity of ecosystems: "Improving the quality of life while living within the carrying capacity of supporting ecosystems". The World Business Council for Sustainable Development (WBCSD) proposed the concept of eco-efficiency [13], and Wuppertal Institute and associates emphasized Factor Four [14]. Furthermore, international academic journals present forums on industrial ecology. In meetings of researchers, the Industrial Transformation project is on-going in the field of International Human Dimension Program on global climate change. Also, there is the Zero Emission Initiative at United Nations University [15].

The 1992 'Earth Summit' in Rio de Janeiro, Brazil, the UN conference on Environment and Development (UNCED) [16], generated not only formal endorsement for the concept of sustainable development by over 150 national governments, but also, a wide range of general and particular policy initiatives under the sustainable development heading. Agenda 21 [17] emerged from the UNCED, which called for development at the local level. Agenda 21 called for the creation of the UN Commission on Sustainable Development (CSD) to ensure effective follow-up of UNCED, enhance international cooperation, and examine progress in implementing Agenda 21 at the local, national, regional and international levels.

The 2002 World Summit on Sustainable Development's (WSSD) Johannesburg Plan of Implementation (JPOI) [18] states that partnerships, as voluntary multi-stakeholder initiatives, contribute to the implementation of inter-governmental commitments in Agenda 21, the Programme 
for the Further Implementation of Agenda 21 and the JPOI. Partnerships serve as a complement but not as a substitute for these commitments. The JPOI also designated the UN CSD to serve as the focal point for discussion on partnerships that promote sustainable development.

This is only a short history of the recent efforts made for sustainable development. Many more declarations and many more meetings have taken place for the promotion of sustainable development.

\section{The Reality}

After all these efforts and the rhetoric that has been flying around in many international institutions, the world today is not in a good shape. It is not even close to approaching any of the definitions of sustainability. One cannot even say that a small step forward has been taken. The facts and the statistics on global income distribution, as well as the poverty that underlies it, are compelling. Over 1.3 billion people, or more than one-fifth of the global population, are estimated to be living at less than one US dollar per day. Other measures of poverty and vulnerability (lack of access to health, education, clean water, or sanitation) yield higher estimates of poverty. Since poverty is concentrated in non-Annex I countries - especially South Asia and Africa -where average per capita income is less than one-quarter (in dollars of constant Purchasing Power Parity) of the average for developed countries [19,20], equity concerns have focused on differences between countries rather than within countries. The distributional dimension of global poverty was illustrated vividly by the Human Development Report 1989 [21], in the form that has come to be known as the champagne glass (Figure 1). This representation of global income distribution shows that in 1988, the richest fifth of the world's population received $82.7 \%$ of the global income, which is nearly 60 times the share of the income received by the poorest fifth (1.4\%). More recent statistics indicate that inequality has widened further since then and that in 1999, the richest quintile received 80 times the income earned by the poorest quintile [13].

Figure 1. Global distribution of income and population.

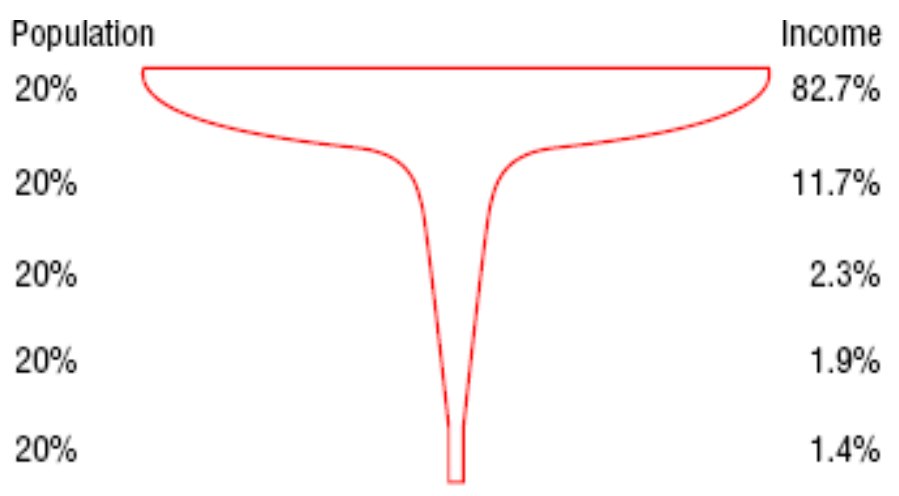

Also, other figures indicate that:

(a) The richest $20 \%$ of the world's population had $82 \%$ of world export markets; the middle-income $60 \%$ had $17 \%$ and the poorest $20 \%$ hardly $1 \%$,

(b) The richest $20 \%$ had $68 \%$ of foreign direct investment; the middle-income $60 \%$ had $31 \%$ and the poorest $20 \%$ hardly $1 \%$, 
(c) The richest $20 \%$ included $93.3 \%$ of users of the Internet; the middle-income $60 \%$ had $6.5 \%$ and the poorest $20 \%$ only $0.2 \%$,

(d) the OECD countries, with $19 \%$ of the global population, had $71 \%$ of global trade in goods and services, $58 \%$ of foreign direct investment and $91 \%$ of all of Internet users,

(e) the world's two hundred richest persons doubled the value of their fortunes in the four years leading up to 1998 to 1 trillion dollars, more, that is to say, than what was owned by $41 \%$ of the world's population.

The Multidimensional Poverty Index (MPI), introduced in the 2010 by the United Nations [22], measures serious deficits in health, education and living standards, looking at both the number of deprived people and the intensity of their deprivations (figure 2). The numbers are staggering.

Figure 2. Multidimensional Poverty Index- A focus on the most deprived

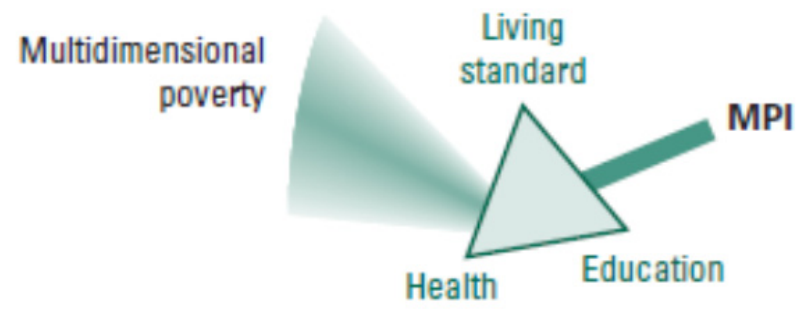

Despite the progress that was achieved in the twentieth century, which is considered as enormous by the UNDP 1999 Human Development Report, poverty and social inequality persist everywhere, both in "the developing" and "the developed" countries. Specifically, in the "developing" countries, there are enormous regional, political and gender inequalities:

- More than a quarter of their 4.5 billion residents had no access to knowledge or to minimum private and public services and their life expectancy did not exceed 40 years,

- Roughly 1.3 billion of their population had no access to clean water,

- Roughly 840 million people were undernourished,

- One in seven children did not have elementary education, etc.

On the other hand, in the industrial or differently called "developed" countries, there are very distinct class and regional inequalities,

- One in eight people in even the richest countries of the world is affected by some of the elements of human poverty, such as long term unemployment, an income below the poverty level, illiteracy, maximum life expectancy of 60 years [23].

\section{The Vision of Integrated Development}

The challenge is to define a development mode that not only combines social needs, economic needs, and environmental needs but also gives a meaning to the lives of the individuals in a society. We will call this worth-living integrated development, to distinguish it from the meaning given to the term "sustainable development". There exists confusion, sometimes deliberately, on the 
international level and on the scientific and political levels, on the significance and perception of "development". At the same time, there exists a rich and important experience from "certain" and wishful, dead-end and inconclusive efforts for development at regional or national level. It is common that a country is characterized based on the extent and the depth of its industrial activity and its production using the term GDP. Based on this criterion, a country is considered "developed" even if it has a high percentage of citizens who live on incomes under the limit of poverty, who are unemployed, working part-time or marginalized, if the quality of public and social services of education, health, security are downgraded, if private interest substitutes progressively even the most obvious government responsibilities, if insecurity, alienation, racism, xenophobia, nationalism in its worst form, prostitution, narcotics, criminality and the intertwining economic and political interests are growing, if ignorance, illiteracy, technical-professional training and re-training, always escalate to more worrying dimensions. GDP has been instituted as the prime economic indicator during the Second World War (to monitor war production). This analysis has been disputed and will continue to be disputed by many scientists, economists, sociologists, biologists, engineers, philosophers etc. in the frame of their work, without however, until today, a cohesive alternative theory for "development" having been constituted. Thus, the need for a publicly acceptable, interdisciplinary and holistic theory of "development", which will be harmonized with the multi-dimensional and holistic nature of the natural and the socio-economic reality which "development" is called to influence "positively" at all the levels, is a major priority [23-25]. There has been a proposal to replace GDP [26-28]. There is the Human Development Index (HDI), used by the UN's Development Programme, which considers life expectancy and literacy as well as standard of living as determined by GDP. The Human Development Index (HDI) is a composite index measuring the average achievements of a country in three basic dimensions of human development [29]: (a) a long and healthy life, measured by life expectancy at birth; (b) knowledge as measured by the adult literacy rate (with $2 / 3$ weight) and the combined primary, secondary and tertiary gross enrolment ratio (with $1 / 3$ weight); (c) living standard, as measured by GDP per capita and adjusted for the local cost of living. Performance in each dimension is expressed as a value between 0 and 1 by applying the following general formula: (maximum target value - minimum target value). The HDI emphasizes that people and their capabilities should be the ultimate criteria for assessing the development of a country, not economic growth. The HDI is annually reported for 177 countries.

The Gender-related Development Index (GDI) takes note of inequalities between any two groups. The two groups considered can in this case be 'male' and 'female' [30]. The indicator can be seen as an adjustment of the HDI components in the following way: (a) Longevity: use of an indicator reflecting mortality rates in younger age groups is preferred; (b) Knowledge; (c) Income: the share of income earned by men and women is derived by calculating their wage as a ratio to the average national wage and multiplying this ratio by their shares of the labor force. Therefore, its result is based both on the ratio of female wages to male wages and on the female to male ratio of the labor force.

The Index of Social Health (ISH) for the USA [31]

The Index of Social Health aims to provide a comprehensive view of social health looking at problems that affect Americans at various stages of their life - childhood, youth, adulthood, and the elderly - as well as problems that affect all ages. The ISH is based on sixteen social indicators, grouped by ages: infant mortality, child poverty, child abuse, teenage suicide, teenage drug abuse, high 
school dropouts, unemployment, wages, health insurance coverage, poverty among the elderly, out-ofpocket health costs among the elderly, homicides, alcohol-related traffic fatalities, food stamp coverage, affordable housing, and income inequality.

The Index of Economic Well-Being (IEWB) [32] covers simultaneously current prosperity (based on measures of consumption), sustainable accumulation, and social topics (reduction in inequalities and protection against social risks). Environmental issues are addressed by considering the costs of $\mathrm{CO}_{2}$ emissions per capita. Consumption flows and wealth accumulation (defined broadly, to include R\&D stock, a proxy for human capital, and the costs of $\mathrm{CO}_{2}$ emissions) are evaluated according to National Accounts methodology [33]. Inequality is monitored with a Gini index [34] and a measure of poverty intensity, the Sen-Shorrocks-Thon index [35].

The Happy Planet Index (HPI) [36] combines environmental impact with individual wellbeing in order to measure the environmental efficiency. It is an index of human wellbeing and environmental impact. The indicator shows the ecological efficiency with which the wellbeing is delivered. It is based on two objective indicators, life expectancy and ecological footprint per capita, and one subjective indicator 'life satisfaction'. Multiplying longevity and the subjective life satisfaction gives the 'degree to which people live long and happily in a certain country at a given time', also called Happy Life Years (HLY). The Ecological Footprint measures the extent to which the ecological demand of human economies stays within or exceeds the capacity of the biosphere to supply goods and services. The (global) target for HPI was set by the New Economics Foundation [37] at 83.5 (on a scale from 0 to 100), based on attainable levels of life expectancy and wellbeing and a reasonably sized EF.

The Genuine Progress Indicator [38] incorporates aspects of social welfare such as income equity, pollution, and access to health care. Furthermore, it is considered to be less complex and more accessible to all people. It balances the costs and benefits of economic activity and growth. In the international community, perhaps the biggest nudge has come from French President Nicolas Sarkozy, who commissioned a report by marquee-name economists, including Nobel laureates Joseph Stiglitz and Amartya Sen, to find alternatives to what he calls "GDP fetishism".

The notion of "economic well-being" [39] is a broader concept than GDP, however can still be captured with standard economic measures. The living conditions include a number of non-material aspects of well-being, and it can be argued that it is the last sphere that is reachable to economic policy. Figure 3 gives a good indication of the elements that comprise happiness and wellbeing.

Bruno Frey [40,41] has analyzed the point of happiness by the extensive recent research on economics of happiness. Human well-being and happiness have manifold sources, with economic indicators and policies influencing them to a certain extent, but under conditional circumstances. An interesting empirical evidence in this regard is shown in figure 4, in the comparison of the US and France.

All the above indices come close to the proposed definition of 'worth-living integrated development' which satisfies the need for this comprehensive dialectical harmony, symmetry and balance in the process of completion of development with the "economic", "social", "political" and "cultural" dimensions. This development is in harmony with nature and traditions, but also with the progress of science and technology. 
Figure 3. The many elements of happiness and well-being

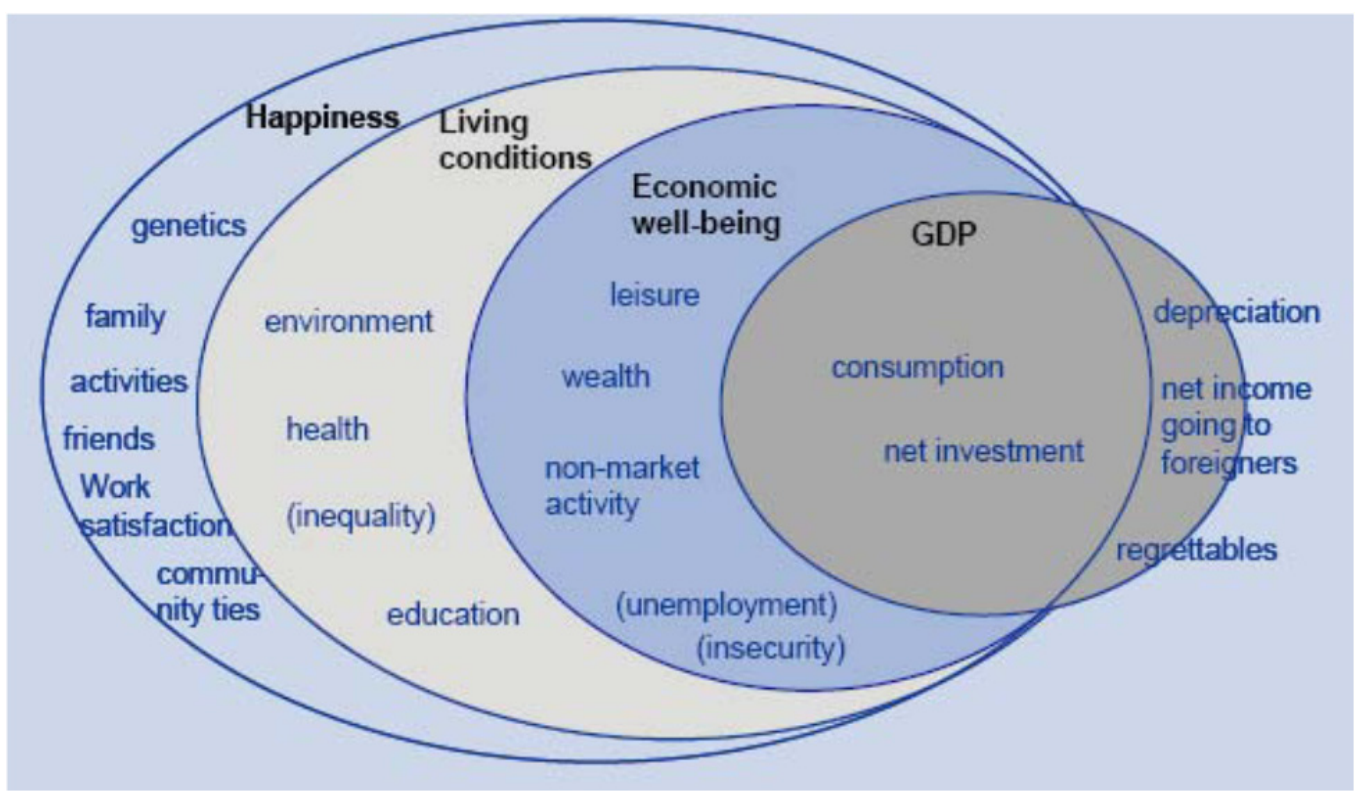

Figure 4. Income, economic well-being and happiness in the USA vs. France [42].

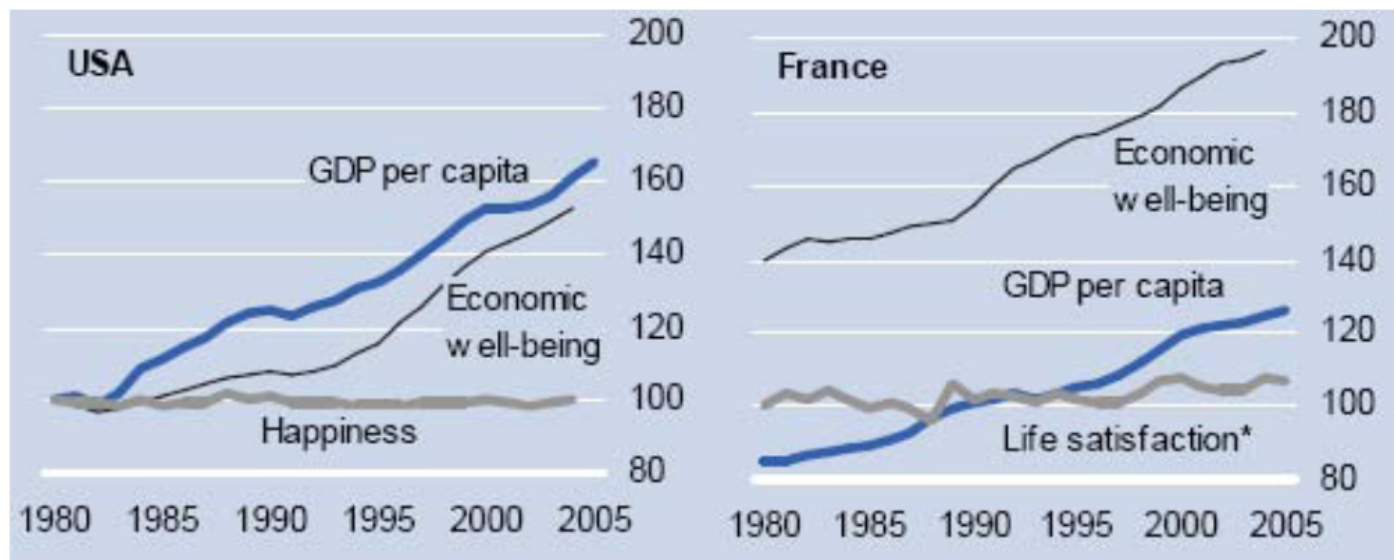

Unfortunately, this is not yet widely understood or accepted by the dominant global superpowers, the global and competitive market, the central banks and the stock exchange markets, or even by the "progressive", "Socialist" or "Social Democratic" political forces, which are unable to formulate an alternative vision and value system for humanity, a system outside and beyond the dominant specifications of the one-dimensional economic development that is based on fierce competition, the so called neo-liberal agenda.

An essential contribution in this direction must be made by the international and national organizations, the governments, the institutions of the state, social and private sectors, the scientists, the politicians and the citizens. There must be an agreement for a common code of communication and comprehension of the significance, values, objectives and content of "development" and its multiple real dimensions. 


\section{The Economic Dimension of Integrated Development}

Economic development is an integral part of the concept of worth-living integrated development. On the basis of its ecumenical character and global scale and importance, economic development incorporates the following elements:

- it does not ignore, but proceeds with and contributes to the social, political and cultural development of all persons on earth, with the development and utilization of the technology appropriate for each case, in the specific territory and time,

- it acknowledges the need for protection of nature, of which all people and their cultures are an integral part, and makes this need an axis of initiatives and actions, at the local, regional, national, transnational and global level.

Thus, an economic development of this nature and quality does not:

- subordinate nature, litter or pollute the natural, socio-economic, political and cultural environment through the irresponsible competition of markets of "developed" countries,

- manipulate science, research and technology by financing them selectively and only if they produce new marketable and profitable products and services,

- squander the natural and human capital of the planet for the sake of maximum immediate profit,

- alienate human beings through the processes of production,

- corrupt consciences, seduce not only politicians, scientists, artists, movements, trade unions, but also workers and the unemployed, exploiting their ambitions, expectations and their insecurities,

- maintain bonds of poverty, ignorance, bad health, lack of food and clean water for the residents of countries in the third world,

- tend to change active, conscious and responsible citizens into passive and fearful individual consumers, under the threat of permanently increasing unemployment [43].

\section{The Political Dimension of Integrated Development}

In the concept of worth-living integrated development and on the basis of its ecumenical character and global scale and importance, the political dimension incorporates the following:

- it does not ignore, but creatively proceeds with and contributes to economic, social and cultural development,

- it essentially aims at the inclusion, at all levels of political and social life, of all people, as free, educated, informed, emancipated, responsible, conscious citizens, who work, produce, create, think and act, individually and collectively, in a way that the promotion of their interests takes into account the rights of all others,

- it is founded on and secured by public schooling/education/culture, to which all have access, independent of race, gender, nationality, color, age and convictions, in order to be part of society and develop the creative possibilities and dexterities of their mind and body, their critical thought and their political and social consciousness and responsibility [43]. 


\section{The Social Dimension of Integrated Development}

The social dimension incorporates the following characteristics:

- it adheres to the human values of peace, justice, solidarity, democracy and rule

- it acknowledges the need for protection of nature, of which all people and their cultures are an integral part, and makes this need an axis of initiatives and actions, at the local, regional, national, trans-national and global level,

- it does not ignore but keeps pace with and contributes to the economic, political and cultural development of all persons on the earth,

- it develops and utilizes the technology which is appropriate in each case in space and time.

Thus, a social development of this nature and quality cannot be:

- limited to "developed" countries only and particularly to the small privileged social classes, in which the relevant (and always ambiguous) "indicators" thrive,

- reconciled with the enormous and permanently expanding and accentuated social inequalities between rich and poor countries, or among social classes within a "developed" or "developing" country.

On the contrary, the social development which is compatible with worth-living integrated development presupposes the subversion of the dominant model of production, distribution and consumption, which is based on overproduction, consolidation of unequal distribution, intensified exploitation of the natural resources of our planet and on the-illogical and without moral barrierscontinuous maximization of market competitiveness, profit, "efficiency" and "effectiveness". It presupposes schools of all levels with structures, operations, programs and content of study which will ensure that the configuration of average social consciousness and social dynamics will not be abandoned to the dominant choices of multinational corporations so as to fit the devastating models of cultural and political homogenization of human societies in the interest of the global markets.

In summary, the key elements that define integrated development are:

- Environment-society-economy integration: ensuring that economic development, social development and environmental protection are integrated in planning and implementation

- Futurity: an explicit concern about the impact of current activity on future generations.

- Environmental protection: a commitment to reducing pollution and environmental degradation and to the more efficient use of resources.

- Equity: a commitment to meeting at least the basic needs of all the people of the present generation (as well as equity between generations).

- Quality of life: recognition that human wellbeing is constituted by more than just income growth.

- Participation: the recognition that integrated development requires the political involvement of all groups or 'stakeholders' in society [43]. 


\section{Environment in Sustainable and Worth-Living Integrated Development}

The dominant perception of the European Union is that "the key to our long-term welfare, in Europe and around the world, is 'sustainable development': finding ways of improving our quality of life without causing harm to the environment, future generations or the people of both the rich and developing world" [28]. Ignoring multi-dimensional, documented critique of the meaningless concept and content of "sustainable development", the European Commission states:

"We particularly need to encourage business to go further, on a voluntary basis and through legislation. Increased attention to environmental measures will improve efficiency and productivity. The expanding market for green goods will lead to increased innovation and expanded job opportunities. European businesses will prosper in this expanding market. The Sixth Environment Action Programme supports and encourages such developments".

Thus, the European Union, consistent with the dominant perception of "sustainable development", entrusts, cedes and assigns responsibility for the environment to corporations, which it encourages, assists and supports in every way.

But what are the somewhat more optimistic prospects for development and environment in the current decade - if there are any? At the theoretical level, the solution could be expected to come from the new and radically different perception, which in critical, interdisciplinary literature, has, directly or indirectly, been documented as worth-living integrated development [12,43-45].

Worth-living integrated development investigates a priori, studies, designs and justifies its actions according to the peaceful, harmonious and creative co-existence and interaction of humanity and nature which is optimum for both, so that multi-dimensional (personal, economic, social, political and cultural) human life is "worth-living" by all, irrespective of national, administrative, political, social, technological and cultural frontiers and differences. It is a "holistic" concept, in agreement with the "whole" nature of the indivisible unity of the natural and the socio-economic reality in each case in each territory and at specific period, and the perpetual human effort to creatively and respectfully transform our common home, the planet Earth. It is not divided into specialist, autonomous, independent, opportunist, fragmentary and frequently contradictory "developmental" choices and actions. It does not give one-dimensional priority to mainly economic considerations over society, politics and culture, without regard for impacts and consequences on human beings and their natural and cultural environment.

Nowadays, no concept of development can exist or be supported, if, like "sustainable development", it involves or permits:

- subordination of nature and life,

- continuing human exploitation of other human beings and nature through modern means,

- enforcement of the will of the strongest party over institutionalized or unwritten rules of international law, justice and humanism, through military, economic, political, technological and cultural means,

- devastation of any social class, nation, social, political, ideological or cultural difference or distinction by any self-appointed "new order' of any type or category, 
- state, police or individual terrorism, which finally aims at the abolition or transformation of human, social and political rights, according to the strategic interests of markets, the new order and their globalization,

- the dominant promotion and enforcement - by all means - of the alleged universal salvation ideologies and the attempt to imprint these in the collective subconscious as new "values", with which all must conform and to which all actions should contribute,

- mass media dominance and apparent or obscure connections with the economy and politics.

The concept, content, perception and the arguments which prove that true development can only be worth-living and integrated, are to be understood and accepted as a theory which contrasts the dominant ideology of the substance-less "sustainable" development.

As an action, worth-living integrated development is the affair of every responsible and conscious scientist, worker, creator and citizen and their collective entities. It must be expressed simultaneously, in space and time, at the cultural, political, social, economic and technical/technological levels, through initiatives and actions which respect the essence of human beings as ethical beings, of life as divine gift, of nature as our most precious, yet fragile common heritage [43].

\section{Conflict of Interest}

The authors declare no conflict of interest

\section{References and Notes}

1. United Nations. Our Common Future; Report of the World Commission on Environment and Development, General Assembly Resolution 42/187: New York, NY, USA, 11 December 1987. Retrieved: 14 November 2007.

2. Lélé, S.M. Sustainable development: a critical review. World Development 1991, 19, 607-621.

3. Perrings, C. Ecological sustainability and environmental control. Structural Change and Economic Dynamics 1991, 2, 275-295.

4. Sustainability and Environmental Policy: Restraints and Advances; Dietz, F.J., Simonis, U.E., van der Straaten, J., Eds.; Edition Sigma: Berlin, Germany, 1992.

5. Actie Plan Duurzaam Nederland (Translated in English in 1993 under the title Action Plan Sustainable Netherlands); Buitenkamp, M., Venner, H., Wams, T., Eds; Friends of the Earth Netherlands: Amsterdam, The Netherlands, 1992/1993.

6. Opschoor, J.B. Industrial Metabolism, Economic Growth and Institutional Change. In The International Handbook of Environmental Sociology; Redclift, M., Woodgate, G. Eds.; Edward Elgar: Cheltenham, UK, 1997; pp. 274-287.

7. Defining and Measuring Sustainability: The Biogeophysical Foundations; Munasinghe, M., Shearer, W., Eds.; The United Nations University and The World Bank: Washington DC, WA, USA, 1995.

8. Banuri, T.; Hoyden, G.; Juma, C.; Rivera, M. Sustainable Human Development, from concept to operation: A guide for the practitioner. UNDP Discussion Paper, NY, USA, 1994.

9. Elkington, J. Cannibals With Forks - The Triple Bottom Line of 21st Century Business; Capstone Publications: London, UK, 1997. 
10. Carley, M.; Spapens, P. Sharing the World: Sustainable Living and Global Equity in the 21st Century; Earthscan: London, UK, 1998.

11. Sachs, W.; Loske, R.; Linz, M. Greening the North: A Post-Industiral Blueprint for Ecology and Equity; Zed Books: New York, NY, USA, 1998.

12. Sachs, W. Planet Dialectics: Exploring in Environment and Development. Fernwood Publishing, Witwatersrand University Press, Zed Books: New York, NY, USA, 1999.

13. Eco-efficiency. World Business Council for Sustainable Development (WBCSD): Geneva, Switzerland, 2000. Available online: http://www.wbcsd.org/web/publications/eco_efficiency_ creating_more_value.pdf (accessed on 30 December 2011).

14. Factor $W$. Wuppertal Institute for Climate, Environment and Energy: Wuppertal, Germany, 2009. Available online: http://www.wupperinst.org/uploads/sbs_dl_list/Factor_W.pdf (accessed on 30 December 2011).

15. Kuehr R. Towards a sustainable society: United Nations University's zero emissions approach. J. Clean. Prod. 2007, 15, 1198-1204.

16. United Nations Conference on Environment and Development (UNCED), Rio de Janeiro, 3-14 June 1992. Available online: http://www.un.org/geninfo/bp/enviro.html (accessed on 30 December 2011).

17. UN Department of Economic and Social Affairs, Division for Sustainable Development. Agenda 21, 1992. Available online: http://www.un.org/esa/dsd/agenda21/ (accessed on 30 December 2011).

18. UN Department of Economic and Social Affairs, Division for Sustainable Development. Johannesburg Plan of Implementation, 11 August 2005. Available online: http://www.un.org/esa/ sustdev/documents/WSSD_POI_PD/English/POIToc.htm (accessed on 30 December 2011).

19. United Nations Development Programme (UNDP). Human Development Report 1999; Oxford University Press: New York, NY, USA, 1999.

20. The World Bank. World Development Indicators. Available online: http:/go.worldbank.org/ 2PFP9HG790 (accessed on 30 December 2011).

21. United Nations Development Programme (UNDP). Human Development Report 1989; Oxford University Press: New York, NY, USA, 1989.

22. Sustainability and Equity: A Better Future for All. United Nations Human Development Report 2011. Available online: http://hdr.undp.org/en/reports/global/hdr2011/download/ (accessed on 30 December 2011).

23. Rokos, D. Development and Environment Policies: From Theories to Practice. In Proceedings of Heleco, Helexpo Exhibition Centre, Athens, Greece, 3-6 February 2005.

24. Rokos, D. The Contribution of Remote Sensing to the Observation, Monitoring and Protection of the Environment. In Environmental Informatics. Methodology and Applications of Environmental Information Processing; Avouris, N.M., Page, B., Eds.; Kluwer Academic Publishers: Dordrecht, The Netherlands, 1995; pp. 183-204.

25. Rokos, D. National, European or Global Strategy for Earth Observation? In Proceedings of the 1st Hellenic National Space Committee Workshop, National Research Foundation: Alternative Editions: Athens, Greece, 26-27 January 1995.

26. Is GDP An Obsolete Measure of Progress? Time Magazine, 30 January 2010. 
27. European Parliament, Policy Department, Economic and Scientific Policy, "Alternative progress indicators to Gross Domestic Product (GDP) as a means towards sustainable development", Brussels, 2007

28. Kropp, M. Overview of Alternative Indicators measuring societal progress. Background paper for the second session of the TURI seminar, European responses to the crisis and alternatives to GDP as an element of a paradigm shift, ITUH Brussels, Belgium, 29 June 2009.

29. United Nations Development Programme (UNDP). Human Development Report 1990; Oxford University Press: New York, NY, USA, 1990.

30. Saith, R.; Harris-White, B. Gender Sensitivity of Well-Being Indicators. United Nations Research Institute for Social Development, Switzerland. Discussion Paper No. 95, September 1998, p. 64. Available online: http://www.unrisd.org/unrisd/website/document.nsf/d2a23ad2d50cb2a280256eb300385855/2e3f47202fad 83dc80256b67005b6ff2/\$FILE/dp95.pdf (accessed on 30 December 2011).

31. Miringoff, M.; Miringoff, M.L.; Opdycke, S. The Social Health of the Nation: How America is Really Doing; Oxford University Press: New York, NY, USA, 1999.

32. Osberg, L.; Sharpe, A. An index of economic well-being for selected OECD countries. Review of Income and Wealth 2002, 48, 291-316.

33. UNSD Publications. National Accounts: A Practical Introduction. Available online: http://unstats.un.org/unsd/pubs/gesgrid.asp?id=311 (accessed on 30 December 2011).

34. Amiel, Y.; Cowell, F.A. Thinking about Inequality. Cambridge University Press: Cambridge, UK, 1999.

35. Encyclopedia of World Poverty. Odekon, M., Ed.; Golson Books, Ltd., Croton-on-Hudson; New York, NY, USA.

36. Marks, N.; Abdallah, S.; Simms, A. The Happy Planet Index, An Index of Human Well-being and Environmental Impact; New Economics Foundation: London, UK, 2006.

37. New Economics Foundation, London. http://www.neweconomics.org/ (accessed on 30 December 2011).

38. Cobb, C.; Halstead, T.; Rowe, J. If the GDP is up, why is America down? The Atlantic 1995, 276, 59-78.

39. Deutsche Bank Research. Measures of well-being; 8 September 2006; Briefing Note.

40. Frey, B. Happiness, economy and institutions. Econ. J. 2000, 110, 918-938.

41. Frey, B. Happiness and Economics: How the Economy and Institutions Affect Human Well-Being; Princeton University Press: Princeton, NJ, USA, 2002.

42. Deutsche Bank Research. Measures of well-being; Briefing Note; 8 September 2006,

43. Rokos, D. From Sustainable to Worthliving Integrated Development (in Greek); A.A. Livanis Publishing: Athens, Greece, 2003; p. 551.

44. Environment 2010: Our Future, our Choice. European Commission, 2001. Available online: $\mathrm{http}: / / w w w . e u r o p a . e u . i n t / c o m m / e n v i r o n m e n t / n e w p r g / i n d e x . h t m$ (accessed on 30 December 2012).

45. Schuurman, F.J. Beyond the Impasse: New Directions in Development Theory; Zed Books: New York, NY, USA, 1993; p. 233.

(C) 2012 by the authors, licensee MDPI, Basel, Switzerland. This article is an open access article distributed under the terms and conditions of the Creative Commons Attribution license (http://creativecommons.org/licenses/by/3.0/). 